\title{
Valor adicionado fiscal no estado do Paraná: concentração e reestruturação regional ${ }^{1}$
}

Jandir Ferrera de Lima²

\begin{abstract}
Resumo
Esse artigo analisa o deslocamento do valor adicionado fiscal e seu padrão de localização entre as microrregiões do Paraná. O procedimento metodológico consistiu na estimativa dos indicadores de localização e da composição da estrutura produtiva a partir de dados do valor adicionado fiscal do Estado do Paraná. A periodização utilizada foi o comparativo entre os anos 2010 e 2017. Os principais resultados apontaram o fortalecimento da economia regional paranaense, com a maior dispersão das atividades produtivas no território estadual e maior geração de valor nas atividades industriais localizadas nas regiões periféricas.
\end{abstract}

Palavras-chave: economia regional, desenvolvimento regional, crescimento econômico, economia paranaense.

\begin{abstract}
This paper analyzes the displacement of tax value added and its location pattern among the regions of Paraná State in Brazil. The methodological procedure consisted in estimating the location indicators and the composition of the productive structure based on data from the tax value added of the Paraná State. The periodization used was between 2010 and 2017. The main results pointed to the strengthening of the regional economy of Paraná, with the greater dispersion of productive activities in the state territory and greater generation of value in the industrial activities located in the peripheral regions.
\end{abstract}

Keywords: regional economy, regional development, economic growth, Paraná State economy.

\section{Introdução}

Na primeira metade do século $X X$, a maioria dos municípios paranaenses tinha sua economia baseada numa estrutura primário-exportadora de produtos in natura, dada às condições de infraestrutura e transformação da época. Outra característica desse período era a forte especialização regional em produtos de alta valorização no mercado nacional ou internacional. As regiões Norte Central e Norte Pioneiro, compreendidas pelos polos de Londrina, Maringá e Cornélio Procópio, tinham no café e na cana-de-açúcar como o "carro-chefe" das suas economias. Já o Oeste do Paraná destacava-se no extrativismo e no cultivo de soja e milho. 0

\footnotetext{
${ }^{1}$ Este texto faz parte de pesquisa financiada com recursos da Fundação Araucária (PR) e do Conselho Nacional de Desenvolvimento Científico e Tecnológico (CNPq).

2 Doutor em Desenvolvimento Regional (UQAC/Canadá). Professor do Programa de Pós-Graduação em Desenvolvimento Regional e Agronegócios da Universidade Estadual do Oeste do Paraná (UNIOESTE). jandir.lima@unioeste.br
} 
Sudoeste paranaense extraia madeira e expandia a pecuária como elementos motores da economia (PADIS, 1981; PIFFER, 1999).

$\mathrm{Na}$ segunda metade do século $X X$, que se iniciou o processo de implantação da infraestrutura básica, seja em transportes quanto em energia, essencial para a transformação industrial e o acesso aos principais mercados. A partir dos anos 1970 o panorama da economia paranaense se modifica, com a geração de valor adicionado em atividades industriais dispersas no espaço e com a mecanização do setor agropecuário. De um lado a indústria transforma e de outro a agropecuária gerando cada vez mais excedentes a serem transformados. Por isso, os segmentos que tiveram maior impulso foram as agroindústrias ligadas à pecuária, ao beneficiamento de grãos e ao ramo madeireiro (PALUDO; BARROS,1995).

Nas décadas de 1980 e 1990, a diversificação e modernização das indústrias ligadas à produção de derivados de celulose, localizadas principalmente na área de abrangência de Guarapuava, no Centro Sul paranaense; o surgimento da indústria têxtil, na região de Campo Mourão, Cianorte e Maringá, nas mesorregiões, Centro Ocidental paranaense Noroeste e Norte Central, respectivamente. O fortalecimento dos frigoríficos em Cascavel, Medianeira, Palotina e Toledo, no Oeste do Paraná e a industrialização nos ramos elétrico e metalúrgico na Região Metropolitana de Curitiba (RMC) vai estimular a existência de duas estruturas econômicas, geradas pelas transformações na base produtiva: a primeira, denominada de Urbana ou Paraná Urbano, na área de influência de Ponta Grossa até Paranaguá, sob a égide da Região Metropolitana de Curitiba (RMC), na qual ocorreram as principais transformações industriais do Estado nos anos 1990. A segunda, denominada de Paraná do agribusiness, abrangendo as demais partes do Estado, com exceção a Foz do Iguaçu. Nestas estão presentes o desenvolvimento da agricultura moderna associada à agroindústria (ROLIM, 1995).

Os anos 1990 marcaram a reestruturação industrial do Paraná, com a queda na especialização e diversificação das atividades tradicionais ligadas à produção de alimentos e o fortalecimento das atividades mais intensivas em capital, conteúdo tecnológico e a especialização nos grupos tecnológicos e componentes na Região Metropolitana de Curitiba (RMC) (NOJIMA, 2002).

De fato, houve a expansão das indústrias de mais alta tecnologia, mas no início do século XXI a retomada do ciclo de investimentos em atividades agroindustriais foi decisiva para sustentar o desenvolvimento regional do Paraná. Primeiro, porque boa parte dos investimentos no ramo agroindustrial se deu em regiões fora das grandes metrópoles. E, segundo, pela 
capacidade de encadeamentos produtivos que os investimentos no setor agroindustrial são capazes de gerar.

Atualmente, dentre as atividades produtivas mais dispersas ao longo do espaço paranaense estão as atividades primárias. Dentro delas, a pecuária e agricultura ganham destaque, tanto que as atividades extrativas minerais e vegetais possuem poucos estudos focando sua dinâmica e localização. Mesmo assim, as atividades extrativas são importantes no contexto de algumas microrregiões do Estado do Paraná, em outras a produção de commodities aliada às atividades a transformação de proteína animal e vegetal dinamizam as atividades urbanas (IPARDES, 2018).

Já a dinâmica do setor secundário o Estado do Paraná ficou ancorada em alguns vetores, quais sejam: o polo automotivo, a modernização do agronegócio, a ampliação quantitativa e qualitativa do complexo madeireiro e papeleiro, a expansão da fronteira internacional e a área de ciência e tecnologia, incluindo o tripé transportes, energia e telecomunicações (LOURENÇO, 2002; SIQUEIRA; SIFFERT FILHO, 2001). Infelizmente, essa dinâmica não se especializou de forma homogênea pelo território paranaense, estimulando a concentração das atividades produtivas. Ela beneficiou, em especial, a Região Metropolitana de Curitiba (RMC). Assim, políticas de desenvolvimento regional em prol das regiões periféricas do Paraná se tornam urgentes, pois o projeto de desenvolvimento via industrialização beneficiou apenas para a Curitiba e seu entorno (NIEHUES, 2014).

Frente ao exposto, esse artigo analisa o padrão de localização do valor adicionado fiscal e seu deslocamento entre as microrregiões do Paraná no início do século XXI. Esse estudo usa uma metodologia quantitativa a partir de indicadores de análise regional para inferir seus resultados. Na segunda seção é apresentado o contexto do desenvolvimento regional paranaense e sua relação com algumas abordagens teóricas. Na terceira seção são apresentados o procedimento metodológico e os indicadores estimados. Na sequência os resultados e discussões e as conclusões dessa abordagem.

\section{Localização das atividades produtivas e desenvolvimento regional}

A questão da concentração das atividades produtivas e a forma como elas se reestruturam ao longo do tempo, beneficiando diferentes regiões em detrimentos de outras, está relacionada ao chamado "problema regional". Para explicar o problema regional ao longo 
do século XX foram formuladas as chamadas teorias da localização e teorias do desenvolvimento regional. No caso do perfil de localização e os critérios pelos quais as firmas escolhem os lugares em que vão gerar produção e, consequentemente, valor adicionado estão relacionados aos fatores locacionais. Esses fatores mudam conforme a atividade produtiva e seus condicionantes de rentabilidade. No caso da localização industrial e, consequentemente, da geração de valor adicionado na indústria, há três fatores que o explicam: o mercado de trabalho, em especial, o volume de trabalhadores qualificados; o mercado de matérias primas, que contribui para minimizar custos de transporte e fortalecera a eficiência; a proximidade do mercado consumidor, que além de minimizar os custos de transporte também fortalece a competitividade da empresa. Além desses três fatores, há autores que consideram também fatores não econômicos, tais como: cultura empresarial, condições de vida ou fatores religiosos; e fatores técnicos e legais, quais sejam: isenções fiscais, estabilidade política, equipamentos públicos, rede de comunicações (AZZZONI, 1985; MARSHALL, 1985; KON, 1999).

Os fatores apontados pelas teorias da localização vão dominar as discussões sobre a economia regional até meados da década de 1950, quando entram cena as teorias do desenvolvimento regional. Essas teorias de um lado tentam explicar o estágio de desenvolvimento das regiões e de outro o processo que as conduziu a modificações na sua estrutura produtiva. Para que a região avance e se desenvolva, além de fatores locacionais, ela deve ser capaz de avançar em algumas características ou premissas, quais sejam: apresentar taxas de crescimento da população, ou seja, a região tem de ser atrativa à força de trabalho; apresentar taxas de crescimento do produto per capita, ou seja, obter ganhos de produtividade dos fatores de produção; estimular a transformação estrutural da economia, alocando a força de trabalho em setores produtivos modernos; as estruturas sociais devem se modificar, estimulando a mobilidade entre as classes sociais; aumentar as forças de atração, fortalecendo a localização das atividades produtivas e atraindo cada vez mais novas atividades; e, estimular a difusão do processo de desenvolvimento econômico regional por meio de encadeamentos produtivos (KUZNETS, 1985; FERRERA DE LIMA, 2016).

Hirschman $(1985,1998)$ identifica os conceitos de encadeamentos à montante e à jusante, que se evidenciam pela ação de certas indústrias fornecedoras e compradoras de insumos. Os encadeamentos à montante de um determinado setor se refletem na proporção do produto total destinado às outras indústrias. Os encadeamentos à jusante induzem ao crescimento de outros setores a eles relacionados, devido às pressões de demanda. Eles se 
refletem na porcentagem de produto que representa a compras de outros produtos do mesmo setor ou de outros setores. Assim, a estratégia mais sólida de crescimento regional é o de combinar os efeitos de encadeamento à jusante e à montante, ou seja, estimular empresas que atraiam outras e associam-se com os mais variados ramos da economia.

A associação geográfica entre as atividades produtivas nada mais é do que as economias de aglomeração, ou seja, pelo adensamento de empresas que surge em determinadas estruturas de produção. Por exemplo, a indústria automobilística atrai uma gama de fornecedores de autopeças junto ao seu parque industrial. Já a agroindústria aglomera um conjunto de produtores de matérias primas no seu entorno. As economias de aglomeração caracterizam as vantagens que as empresas auferem ao estarem próximas, como a diminuição nos custos de transações, ganhos em termos de logística e a cooperação técnica. Nesse aspecto, Krugman (1991) salienta que a concentração, e com ela a polarização, é o resultado da interação entre baixos custos de transporte e de relações interindustriais de cooperação e concorrência em regiões específicas. As regiões que ganham devem oferecer os menores custos de transporte e menos dependência nas atividades de transformação e serviços com maior retorno de escala.

O resultado final de todo o processo de criação de encadeamentos produtivos, diminuição nos custos de transação e melhoria nas infraestruturas de transporte gera rupturas estruturais. Ou seja, as aglomerações se fortalecem e avançam no processo de desenvolvimento econômico a partir de modificações na divisão social do trabalho e a transição de uma estrutura mais urbanizada, seja ela urbana-industrial ou urbana-rural (SILVA; FERRERA DE LIMA, 2014).

Para algumas atividades produtivas, como a agroindustrial, tem uma natureza mais propensa a gerar encadeamentos produtivos. Os efeitos em cadeia ou encadeamentos produtivos produziram dinamismos na economia regional, tanto pelos investimentos na implantação e ampliação de atividades produtivas, quanto pelas compras de insumos e transferências tecnológicas para atividades primárias (RIPPEL; FERRERA DE LIMA, 2009).

\section{Procedimentos metodológicos}

A variável utilizada nesse estudo foi o valor adicionado fiscal em reais ( $R \$$ ) deflacionado pelo Índice Nacional de Preços ao Consumidor (INPC). Segundo IPARDES (2019), o valor adicionado fiscal é a diferença entre o valor das saídas das mercadorias e o valor das entradas de mercadorias e serviços recebidos em uma empresa a cada ano civil, acrescido do valor das 
prestações de serviços tributáveis pelo ICMS. Para fins de análise, a geração do valor adicionado fiscal foi dividida em três setores econômicos: primário, secundário e terciário.

Os dados do valor adicionado fiscal foram coletados junto ao Banco de Dados Estadual (BDE) do Instituto Paranaense de Desenvolvimento Econômico e Social (IPARDES). A periodização utilizada foi o comparativo entre 2010 e 2017 . O ano de 2010 marcou um crescimento econômico significativo na economia brasileira, na faixa de $7,5 \%$ ao ano o que impactou e se refletiu nas economias regionais. Já o ano de 2017 marca o último período da crise econômica e a recessão que se abateu sobre a economia brasileira a partir de 2015, o que marca o segundo decênio do século XXI.

A divisão regional escolhida para atender aos objetivos dessa análise foi a da microrregião. Para fins de análise, os termos "microrregião" e "região" são utilizados como equivalentes.

Figura 1: Microrregiões do Estado do Paraná - 2019.

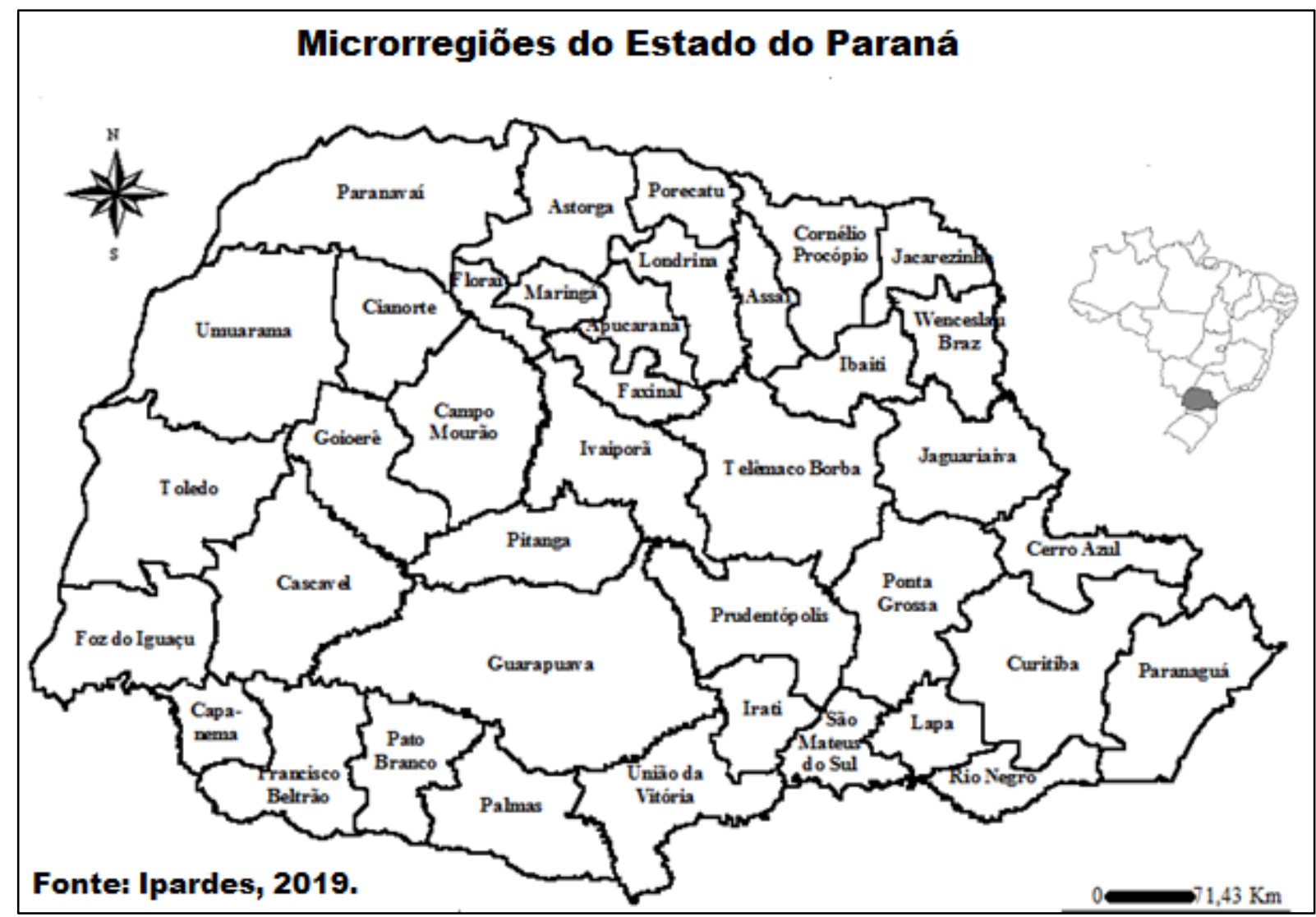

Para definir o padrão de localização do valor adicionado fiscal (VAF) e seu deslocamento entre as regiões paranaenses, esse estudo se baseou nos textos clássicos de Haddad (1989), Costa (2002), Ferrera de Lima (2006) e Alves (2012). 
No caso do valor adicionado fiscal nos diferentes setores econômicos, na equação ele é representado como V. Então, $V_{i j}$ é o valor adicionado no setor econômico "i" na microrregião "j". Para relacionar a distribuição percentual de V e captar o padrão de concentração locacional ou de deslocamento da geração de VAF ao longo do tempo, utilizou-se $V_{i j}$ em dois períodos distintos estimando um indicador de deslocamento ou deslocalização, no caso Idd, sendo:

$$
I d d=\sum_{j}\left[\left|V_{i j}^{A 0} \div \sum_{j} V_{i j}-V_{i j}^{A 1} \div \sum_{j} V_{i j}\right|\right] \div 2
$$

Em que, $A_{o}$ é o período inicial de análise, no caso o ano 2010, e $A_{1}$ o período final de análise, no caso o ano de 2017; sendo $V_{i j}$, o valor adicionado fiscal (VAF) no setor ou especialização "i" na microrregião "j". No caso, o Idd terá variações dentro do intervalo de 0 a 1 , no qual a maior proximidade da unidade (1) reflete um deslocamento da geração de valor adicionado mais significativa. A partir do Idd também se pode estimar a reestruturação produtiva, ou seja, enquanto o Idd observa o deslocamento espacial dos setores econômicos entre as regiões, o Indicador de reestruturação (Ireest) indica as mudanças na estrutura produtiva intra-regional, o que leva a uma maior ou menor especialização produtiva. A equação 02 apresenta a forma de estimativa do Ireest:

$$
\text { Ireest }=\sum_{i}\left[\left|V_{i j}^{A 1} \div \sum_{i} V_{i j}-V_{i j}^{A 0} \div \sum_{i} V_{i j}\right|\right] \div 2
$$

O Ireest varia entre zero e um e quando mais próximo da unidade (1) indica uma reestruturação significativa na especialização produtiva intrarregional. Ao contrário, mais próximo à zero a reestruturação foi pouco significativa. Enquanto o indicador de deslocamento foca na redistribuição das atividades produtivas entre as microrregiões, o indicador de reestruturação analisa a composição setorial da economia da região apontando mudanças nessa estrutura que conduziram a uma maior ou menor especialização na geração do VAF.

A partir do desdobramento das equações 01 e 02 se observa a Concentração Locacional (CLi) do valor adicionado fiscal (V), sendo:

$$
C L i=\sum_{j}\left|\left(V_{i j} / \sum_{j} V_{i j}\right)-\left(\sum_{i} V_{i j} / \sum_{i} \sum_{j} V_{i j}\right)\right| \div 2
$$

Em que, $V_{i j}$, é o valor adicionado fiscal no ramo ou especialização “i” na microrregião "j". A Concentração Locacional (CLi) relaciona a distribuição percentual do valor adicionado fiscal numa atividade entre as microrregiões com a distribuição percentual do valor da produção no conjunto do Estado do Paraná. Ou seja, seu indicador varia num intervalo $\geq 0 \leq 1$. Para os valores 
iguais a zero (0), a atividade $i$ estará distribuído regionalmente da mesma forma que o conjunto de todas as atividades. Se o valor for igual à unidade (1), a atividade setor $i$ apresenta um padrão de concentração regional mais intenso do que o conjunto de todos os setores econômicos. A análise toma como padrão o intervalo entre zero e um, pois a homogeneidade nos extremos do indicador só seria possível como uma homogeneidade ou heterogeneidade absoluta, o que é impossível para a estrutura produtiva.

Geralmente, as regiões mais dinâmicas possuem maior vantagem competitiva, em função do seu perfil de especialização e condições de localização, como infraestrutura, mão de obra diferenciada, etc... As regiões mais especializadas tendem a auferir maiores ganhos de produtividade ao longo do tempo. Assim, sua relação custo/unidade produzida cai, permitindo à empresa uma melhora nas suas margens de lucro para competir via preços. Como a variável utilizada nessa análise é o valor adicionado fiscal, a melhoria nos preços, na demanda ou na quantidade produzida em função de uma maior quantidade de investimentos ou melhorias na renda ou produtividade tende a fortalecer o perfil locacional (COSTA, 2002; SOUZA; SOUZA, 2004).

\section{Resultados e discussões}

A Tabela 1 apresenta os resultados das estimativas dos indicadores de deslocamento e de reestruturação do valor adicionado fiscal (VAF) do Estado do Paraná nos períodos 2007 e 2017.

Tabela 1: Paraná: deslocamento e reestruturação do valor adicionado fiscal regional nos setores econômicos (2010/2017).

\begin{tabular}{lcc}
\hline Setor & $\begin{array}{c}\text { Deslocamento regional } \\
(\mathrm{Idd})\end{array}$ & $\begin{array}{c}\text { Reestruturação regional } \\
\text { (Ireest) }\end{array}$ \\
\hline Primário & 0,0381 & 0,0457 \\
Secundário & 0,0692 & 0,0571 \\
Terciário & 0,0438 & 0,0475
\end{tabular}

Fonte: resultados da pesquisa e dados do Ipardes (2019)

Pelos resultados da pesquisa expostos na Tabela 01, o setor secundário apresentou a maior reestruturação em termos de especialização produtiva, o que conduziu a um maior deslocamento na sua localização setorial. O setor secundário é o mais significativo na geração do VAF e um padrão de concentração bem diferenciado do restante dos setores econômicos. Os 
setores primário e secundário apresentaram um padrão de reestruturação na sua especialização, mas por outro lado o setor primário não apresentou um deslocamento significativo na geração de VAF.

Para corroborar com os dados da Tabela 1, os dados do Ipardes (2019) apontaram que a distribuição percentual do VAF entre as regiões apontou que em 2010 a microrregião de Curitiba gerava $54,10 \%$ do VAF estadual. Em 2017, esse número recuou para 44,10\%. Ou seja, o deslocamento da localização do VAF foi significativo em $10 \%$ de perda de participação, mas a microrregião de Curitiba continuou concentrando boa parte da geração e riqueza no Paraná. A perda de posição de Curitiba reforçou a posição e outras regiões interioranas, como a microrregião de Foz do Iguaçu, cuja participação na distribuição estadual na geração de VAF em 2010 era de 5,17\% e aumentou para 6,21\% em 2017.

No mesmo período, Londrina avançou de 4,12\% para 4,54\% em 2017; Maringá saiu de 2,78\% para 3,58\% em 2017; Telêmaco Borba foi de 1,73\% para 3,84\%; Toledo de 2,14\% para 3,22\%; Ponta Grossa de 4,63\% para 5,66\%; Cascavel de 2,15\% para 2,68\%; Pato Branco 1,67\% para 2,81\% e Apucarana de 2,45\% para 2,63\%; Guarapuava de 1,90\% para 2,08\% e, dentre outros. Ou seja, as microrregiões do interior do Paraná absorveram as perdas da região de Curitiba e expandiram a geração de valor adicionado. Ao final do ciclo de recessão o interior paranaense fortaleceu sua posição no setor secundário.

O fortalecimento das regiões não metropolitanas paranaenses em geração de VAF industrial está ligado também ao cooperativismo. Ao final do primeiro decênio do século XXI, surgiram mais de 45 novas cooperativas cuja maior parte foi do ramo agropecuário. Isso gerou mais de 600 mil empregos e um aumento no faturamento de mais de $300 \%$ chegando $\mathrm{R} \$ 22$ Bilhões. Sem contar no maior incremento na industrialização de produtos básicos, agregando valor no interior do Paraná em detrimento dos principais centros urbanos do estado (CAZAROTTO; PEREIRA, 2012).

Tabela 2 - Paraná: concentração regional (CLi) do valor adicionado fiscal nos setores econômicos (2010/2017).

\begin{tabular}{lcc}
\hline Setor & 2010 & 2017 \\
\hline Primário & 0,48 & 0,43 \\
Secundário & 0,13 & 0,14 \\
Terciário & 0,11 & 0,13 \\
\hline
\end{tabular}

Fonte: resultados da pesquisa a partir de dados do Ipardes (2019) 
Os resultados do padrão de concentração locacional indicaram uma tendência à desconcentração do setor primário, ou seja, mais microrregiões se destacaram na geração de VAF. Os resultados do setor primário foram mais intensos que os resultados do setor secundário. Apesar da perda de posição da microrregião de Curitiba, a geração de VAF se deslocou para as microrregiões já industrializadas, com exceção e Telêmaco Borba, cujo avanço na produção de celulose e papel e a expansão das áreas de reflorestamento colocaram a microrregião numa posição mais efetiva na distribuição do VAF, passando as microrregiões de Pato Branco e Toledo.

Esses resultados demonstram uma mudança de perfil de localização do setor primário. Entre 1988 e 2012, um estudo de Silva e Ferrera de Lima (2015), sobre as mudanças estruturais na economia paranaense, apontou concentração do emprego formal no setor primário da economia em decorrência da dispersão espacial da população em municípios com continuum urbano-rural bem significativo. Além disso, no conjunto das regiões paranaenses, menos de $50 \%$ delas concentravam atividades ligadas à avicultura e suinocultura, que são geradoras de postos de trabalho no meio rural.

Porém, os dados do perfil de geração de VAF entre 2010 e 2017 apontaram a tendência à dispersão das atividades primárias, enquanto geradoras de riqueza, ao longo do espaço paranaense. A melhor redistribuição das atividades primárias no Paraná também foi corroborada pelo estudo de Mattei; Mattei (2017) ao analisar a localização e especialização da Região Sul do Brasil. As autoras apontaram, por meio de métodos de análise regional e usando o emprego formal como variável-chave, que o Paraná teve maior destaque na agropecuária em relação ao Rio Grande do Sul e Santa Catarina, entre 2010 e 2015. No Paraná, enquanto os empregos industriais se mantiveram estáveis nesse período, o crescimento do emprego na agropecuária, pesca, caça e extração vegetal cresceu 3,8\%. Já o emprego formal nos ramos de comércio e serviços cresceu $18 \%$.

Enquanto o setor terciário reflete as cidades mais adensadas em população, o setor primário reflete a pujança das cidades com um continuum urbano-rural mais significativo. Isso ficou comprovado num estudo de Bernardelli et al (2018), sobre a formalização do trabalho na agricultura, que mostrou aumento na empregabilidade rural no Paraná no entre 2006 e 2016. Outro fator importante em relação à formalização dos trabalhadores foi seu perfil educacional. O aumento no nível de escolaridade e a formalização dos trabalhadores rurais também contribuíram para o aumento na renda per capita e na renda total das regiões paranaenses. Isso 
significa uma melhora no mercado consumidor das regiões e, consequentemente, um impacto direto sobre o VAF regional e municipal.

\section{Considerações finais}

Esse artigo analisou o deslocamento do valor adicionado fiscal e seu padrão de localização entre as microrregiões do Paraná no segundo decênio do século XXI. Para definir o padrão de localização do valor adicionado fiscal e seu deslocamento entre as microrregiões paranaenses foram utilizados os indicadores de deslocamento, reestruturação e concentração. Eles foram estimados a partir de dados setoriais do valor adicionado fiscal junto ao Banco de Dados Estadual (BDE) do Instituto Paranaense de Desenvolvimento Econômico e Social (IPARDES). A periodização utilizada foi o comparativo entre 2010 e 2017.

Os resultados demonstraram que a economia paranaense se fortaleceu no período estudado, tanto em relação à Região Sul do Brasil, quanto em termos de diversificação e dispersão regional das atividades produtivas. Outro resultado importante foi o deslocamento da geração de valor nas atividades primárias. Essas atividades estavam mais concentradas em 2010, mas em 2017 já apresentaram uma maior dispersão na geração de valor ao longo do espaço paranaense.

Outro deslocamento importante foi ligado ao setor secundário da economia. As atividades de transformação agroindustrial, capitaneadas pelas cooperativas agroindustriais, têm sido bem intensas no interior do Estado do Paraná. Isso fortaleceu regiões periféricas em relação às regiões metropolitanas e colocou a economia paranaense em um novo patamar industrial no interior no início do século XXI. É certo que esse novo padrão locacional demanda mais estudos para compreender suas tendências de espraiamento e de fortalecimento das cadeias produtivas, mas já apontam um reposicionamento do Oeste e Sudoeste do Paraná na participação do valor adicionado bruto.

Por fim, os estudos sobre o perfil de localização, sobre as tendências à concentração e as tendências ao deslocamento das atividades produtivas não se esgotam nesse estudo. Pesquisas mais amplas, com a utilização de um conjunto mais amplo de variáveis e métodos estatísticos mais robustos, são recomendadas para se inferir resultados mais precisos sobre a localização das atividades produtivas no Paraná. Porém, os resultados preliminares aqui apontados já fornecem pistas e subsídios para novas hipóteses para futuras pesquisas. 


\section{Referências}

ALVES, L. Indicadores de localização, especialização e estruturação Regional. In: PIACENTI, A.C.; FERRERA DE LIMA, J. (Org.) Análise regional: Metodologias e Indicadores. Curitiba, PR: Camões, 2012: 33-49.

AZZONI, C. R. Onde Produzir? Aplicações da teoria da localização no Brasil. Instituto de Pesquisas Econômicas, IPE-USP, São Paulo, 1985.

BERNARDELLI, L.V.; PASCHOALINO, P.A.; GOBI, J.R.; MICHELLON, E. A Formalização do Trabalho na Agricultura: uma análise das microrregiões do Estado do Paraná. Revista Paranaense de Desenvolvimento, $\mathrm{n}$ ㅇ 135, p.47-67, 2018.

CAZAROTTO, S.; PEREIRA, W. As cooperativas de produção agroindustrial no Paraná e o Banco Regional de Desenvolvimento do Extremo Sul (BRDE) como seu agente indutor de desenvolvimento. Revista Paranaense de Desenvolvimento, no 122, p. 177-200, 2012.

COSTA, J. S. Compêndio de Economia Regional. APDR. Coimbra: Gráfica de Coimbra Ltda. Lisboa: APDR, 2002.

FERRERA DE LIMA, J. Méthode d'analyse regionale: indicateurs de localisation, de structuration et de changement spatial. Collection notes et rapports de recherche du GRIR. Saguenay, Canadá : UQAC/GRIR, 2006.

FERRERA DE LIMA, J. O espaço e a difusão do desenvolvimento econômico regional. In: PIACENTI, C.A.; FERRERA DE LIMA, J. EBERHARDT, P.H. (orgs.). Economia e desenvolvimento regional. Foz do Iguaçu: Editora Parque Itaipu, p. 15-40. 2016.

HADDAD, P. R. Economia regional: teoria e métodos de análise. Fortaleza: BNB/ETIENE, 1989. HIRSCHMAN, A. Auto subversão. São Paulo: Companhia das Letras, 1998.

HIRSCHMAN, A. Desenvolvimento por efeitos cadeia: Uma abordagem generalizada. In: SORJ, B.; CARDOSO, F.H. (Org.) Economia e movimentos sociais na América Latina. São Paulo: Brasiliense, p. 31-79, 1985.

IPARDES - INSTITUTO PARANAENSE DE DESENVOLVIMENTO ECONÔMICO E SOCIAL. Dados diversos do BDE. Disponível em: www.ipardes.pr.gov.br. Acesso em: 03 de abril de 2019.

KON, A. Novas territorialidades: Transformações nas hierarquias econômicas regionais. Pesquisa \& Debate, v.10, nº 01, p. 42-76, 1999.

KRUGMAN, P. Increasing returns and economic geography. Journal of Political Economy, n99, p.483-499, 1991.

KUZNETS, S. S. Crescimento econômico moderno: descobertas e reflexões. Revista Brasileira de Economia. v. 39, n² 2, p. 255-39, 1985.

LOURENÇO, G.N. Cenários de compreensão da dinâmica econômica paranaense. In: CARIO, S.A.F.; PEREIRA, L.B.; BROLLO, M.X. (Org.) Economia Paranaense: estudos de ramos selecionados. Florianópolis: UFSC, p.19-36, 2002.

MARSHALL, A. Princípios de economia: tratado introdutório. Coleção Os Economistas. São Paulo: Nova Cultural, 1985.

MATTEI, T.; MATTEI, T. Métodos de análise regional: um estudo de localização e especialização para a Região Sul do Brasil. Revista Paranaense de Desenvolvimento, no 133, p. 227-243, 2017. 
NIEHUES, L. G. A Industrialização do Paraná: abordagens de um processo de desenvolvimento concentrado. Geographia Opportuno Tempore, vol.1, número especial, p.454-466, 2014.

NOJIMA, D. Crescimento e reestruturação industrial do Paraná 1985/2000. Revista Paranaense de Desenvolvimento, $n^{\circ}$ 103, p.23-43, 2002.

PADIS, P. C. Formação de uma economia periférica: o caso do Paraná. São Paulo: Editora Hucitec, 1981.

PALUDO, G. B.; BARROS, D. A. Síntese da história do Paraná. Cascavel: Assoeste, 1995.

PIFFER, M. Apontamentos sobre a base econômica da região Oeste do Paraná. In: CASSIMIRO FILHO, F.; SHIKIDA, P. F. A. (Org.). Agronegócio e desenvolvimento regional. EDUNIOESTE, p. 57-84, Cascavel, 1999.

RIPPEL, R.; FERRERA DE LIMA, J. Polos de crescimento econômico: notas sobre o caso do Estado do Paraná. Redes, vol. 14, no 01, p. 136-149, 2009.

ROLIM, C. F. C. O Paraná urbano e o Paraná do agrobusiness: as dificuldades para a formulação de um projeto político. Revista Paranaense de Desenvolvimento, № 93 p. 31-55, 1995.

SILVA, A. C.; FERRERA DE LIMA, J. Divisão social do trabalho e ruptura estrutural: o caso da economia paranaense. Anais VII Seminário Internacional de Desenvolvimento Regional.

Globalização em Tempos de Regionalização - Repercussões no Território Santa Cruz do Sul: UNISC, 2015. Disponível em:

https://online.unisc.br/acadnet/anais/index.php/sidr/article/view/13341/2507. Acesso em: 23/06/2019.

SILVA, A.C.; FERRERA DE LIMA, J. O Conceito de ruptura estrutural no desenvolvimento econômico regional. Pensamento Plural, no15, p. 133-149, 2014.

SIQUEIRA, T. V.; SIFFERT FILHO, N. F. Desenvolvimento regional no Brasil: tendências e novas perspectivas. Revista do BNDES, vol. 08, n 16, p. 79-118, 2001.

SOUZA, N. J.; SOUZA, R. B. Dinâmica estrutural-diferencial da região Metropolitana de Porto Alegre, 1990-2000. Revista de Economia, vol. 30, no 02, p. 121-144, 2004. 